\title{
Gobernanza e integración de familias rurales a cadenas pecuarias: el caso del ejido Cobachi, Sonora*
}

\author{
(Governance and Integration of Rural Families to Livestock Production \\ Chains: the Case of Ejido Cobachi, Sonora) \\ Araceli del Carmen Andablo Reyes, ${ }^{* *}$ María del Carmen Hernández

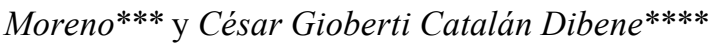

\section{RESUMEN}

La integración de las familias rurales al sistema agroalimentario globalizado se ha logrado a través de una creciente especialización productiva y a costa de la capacidad para generar sus propios alimentos. Asimismo, estas familias han ido perdiendo autonomía para decidir qué, cuánto y cómo producir, el uso que dan a sus recursos naturales, así como cuáles insumos y canales de distribución utilizar. Aquí se presenta un estudio de caso sobre la pérdida de gobernanza en la ganadería familiar sonorense, que se integra tanto a la cadena global de la carne de bovino mediante la cría de becerros para la industria cárnica estadounidense, como ala cadena lechera local con la elaboración de queso fresco. Los resultados revelan la posición de desventaja de las familias rurales en la cadena global, en comparación con el alto nivel de gobernanza que han logrado en la cadena local.

Palabras clave: gobernanza, ganadería familiar, cadenas de valor, queso, becerros. Clasificación JEL: Z13.

\begin{abstract}
The integration of rural households to global food system has been achieved through increased specialization at the expense of the ability to produce their own food. Also, these families have lost autonomy to decide what, how much and how to produce, the use of their natural resources, the inputs and distribution channels used. This article aims to illustrate the loss of governance of these production units, with a case study of Sonoran livestock families, that are integrated both in global chain of beef cattle, through the raising calves for the US meat industry, as in the local chain of milk by producing cheese. The results reveal the disadvantages of families in the global chain, compared with the high level of governance that they have achieved in the local chain.
\end{abstract}

Keywords: governance, family livestock, value chains, cheese, calves. JEL classification: Z13.

* Fecha de recepción: 06/05/2013. Fecha de aprobación 13/01/2015. La información utilizada en el presente trabajo se deriva de Catalán (2012), tesis de licenciatura realizada en el marco del proyecto "Laboratorio de innovación para la producción inocua y sustentable de alimentos en comunidades rurales", del Centro de Investigación en Alimentación y Desarrollo, AC.

** Investigadora de la Coordinación de Desarrollo Regional del Centro de Investigación en Alimentación y Desarrollo, AC. Tel.: (662) 28924 00. Correo electrónico: aandablo@ciad.mx.

*** Investigadora de la Coordinación de Desarrollo Regional del Centro de Investigación en Alimentación y Desarrollo, AC. Tel.: (662) 28924 00. Correo electrónico: mar@ciad.mx.

**** Estudiante de la Maestría en Desarrollo Regional del Centro de Investigación en Alimentación y Desarrollo, AC. Tel.: (662) 28924 00. Correo electrónico: gioberti88@gmail.com. 


\section{INTRODUCCIÓN}

El siglo XXI concluyó su primera década evidenciando las debilidades del paradigma neoliberal tanto en los ámbitos financiero y energético como en el llamado sistema agroalimentario globalizado. Esto último se refiere a una compleja red de relaciones asimétricas de producción, distribución y consumo de alimentos dirigida por unas cuantas grandes corporaciones con presencia multinacional (Chauvet, 2010), en la que se ha reordenado la geografía de la producción primaria de alimentos bajo el principio de las ventajas comparativas, una de las principales estrategias derivadas del Consenso de Washington (Marchione, 2008, citado en Hernández, Andablo y Ulloa, 2012). En esta perspectiva, la agricultura pasó a ser una actividad económica más que debía regirse por los criterios de competitividad y producir bienes de acuerdo con sus mayores fortalezas para el mercado. Así, la seguridad alimentaria se orientó a garantizar la disponibilidad de alimentos al menor costo, sin importar su origen geográfico, generando en el ámbito local una ruptura en el vínculo producción-consumo, lo que en algunas economías se manifestó en una creciente dependencia alimentaria (Hernández, Andablo y Ulloa, 2012).

Si esto ha ocurrido en el terreno productivo, en el social es posible afirmar que este modelo agroalimentario intensificó la exclusión de millones de unidades rurales familiares (URF) ${ }^{1}$ en todo el mundo, al resultar incapaces de mantenerse como productores de alimentos bajo las nuevas reglas del juego. Y las que lo han logrado, ha sido a través de una creciente especialización productiva y a costa de la capacidad para generar sus propios alimentos. De manera paralela, estas familias rurales han ido perdiendo autonomía para decidir qué, cuánto y cómo producir, el uso que dan a sus recursos naturales, así como cuáles insumos y canales de distribución utilizar. Lo anterior, ha significado la pérdida de gobernanza en las cadenas productivas donde se insertan.

Desde la perspectiva de Gereffi, Humphrey y Sturgeon (2005, p. 79), la gobernanza define el posicionamiento de los actores involucrados en las cadenas globales de valor y la forma en que éstos se integran no sólo afecta a los propios

\footnotetext{
1 "Forma de organización económica fincada en el trabajo familiar, mediante la explotación de los recursos naturales, alternada con otras actividades desarrolladas dentro y fuera de la unidad de producción, en donde se utilizan conocimientos trasmitidos de generación en generación, a través de prácticas de sostenimiento económico cotidianas" (Ley de Desarrollo Rural Sustentable del Estado de Sonora, 2009, p. 13). En este texto se usaran como sinónimos los términos "unidades rurales familiares", "familias rurales", "agricultura familiar", "unidad familiar".
} 
participantes en estas cadenas, sino también determina cómo y por qué los países avanzan o no en la economía global. A nivel básico, la gobernanza se refiere a los procesos de interacción entre los actores involucrados en una cadena de valor que conducen a la toma de decisiones sobre la asignación de recursos y la distribución de los beneficios.

Particularmente en México, la posición desventajosa de las URF en el sistema agroalimentario se agudizó durante las recientes crisis alimentarias. La inestabilidad de los precios internacionales de alimentos básicos que empezara en 2006 volcó, aunque de manera coyuntural, la preocupación de las naciones hacia la satisfacción de su demanda interna. En el caso mexicano, hasta antes de la apertura comercial, las familias rurales habían sido protagonistas de la oferta local de alimentos básicos. Sin embargo, las recientes crisis han sorprendido al país con una base productiva rural desmantelada por el éxodo y la pauperización de las unidades familiares, que han sido excluidas del actual orden agroalimentario: entre 1980 y 2010, la población que habitaba en localidades menores de 2500 habitantes disminuyó en más de diez puntos porcentuales respecto al total nacional (INEGI, 1980; 2010) y entre 1992 y 2010, la población considerada en pobreza de patrimonio ${ }^{2}$ (CONEVAL, 2010), se incrementó en el medio rural de 22.9 a 25.6 millones de personas. Esta dinámica social se explica en mucho por la exclusión de gran parte de los agricultores familiares como proveedores de alimentos (Chauvet, 2010), pero también porque quienes lograron vincularse a los nuevos esquemas tuvieron que especializarse, sobreexplotar sus recursos naturales en aras de mantenerse integrados y subordinar su producción de alimentos a las necesidades del mercado (Hernández, Andablo y Ulloa, 2011).

El presente estudio de caso se propone ejemplificar la pérdida de gobernanza de las URF en las cadenas de valor global en el ámbito de la ganadería familiar del estado mexicano de Sonora que participa en dos cadenas productivas: la cadena globalizada de la carne de bovino, a través de la cría de becerros para la industria cárnica de EU, y la cadena local de lácteos, en la que participan como proveedoras de queso fresco, de gran arraigo en la cocina tradicional de esa entidad. Mediante la comparación de ambas cadenas, se contrasta su posición de desventaja en la global con el alto nivel de gobernanza que estas mismas familias disfrutan en la cadena local. En un contexto donde la política económica conti-

\footnotetext{
${ }^{2}$ La pobreza de patrimonio se refiere a la población con "insuficiencia de ingreso disponible para adquirir la canasta alimentaria y efectuar los gastos necesarios en salud, educación, vestido, vivienda y transporte, aun si se hiciera uso de todo el ingreso disponible en el hogar exclusivamente para la adquisición de estos bienes y servicios" (CONEVAL, 2010).
} 
núa favoreciendo el desarrollo hacia el exterior y, por ende, la integración a las cadenas globales, es relevante realizar este ejercicio comparativo por el alto impacto que el nivel de gobernanza tiene en el desarrollo territorial del campo y en la eficiencia colectiva de las comunidades rurales. Como indicadores de gobernanza se eligieron dos variables utilizadas por Gereffi, Humphrey y Sturgeon (2005); una es la complejidad en las transacciones, que a su vez comprende tres categorías de análisis: tipo de relaciones, características del producto y condiciones de producción y establecimiento del precio del producto. La otra variable se refiere a la capacidad de las URF para cubrir la demanda de la siguiente fase de circulación del producto e incluye dos categorías de análisis: recursos de la unidad familiar destinados a la cadena y representatividad de la producción respecto a la demanda. Una tercera variable agregada es la participación de las familias rurales en los ingresos generados en la cadena productiva.

Para realizar esta comparación, se eligió el caso de las URF del ejido Cobachi, municipio de La Colorada, estado de Sonora, y se tomó como referencia el ejercicio realizado por Gereffi, Humphrey y Sturgeon (2005), quienes elaboraron una tipología de la gobernanza en las cadenas de valor, la cual se expone en el primer apartado de este trabajo, donde también se definen los conceptos básicos que orientan el análisis de caso. En una segunda sección se expone la estrategia metodológica seguida en el estudio. En la siguiente se exponen los principales resultados de las variables de gobernanza en cada cadena pecuaria, que se identifican, de acuerdo con la tipología mencionada, como de gobernanza cautiva la de carne, por el control ejercido por la industria estadunidense sobre las condiciones de producción de las URF, y como de gobernanza relacional a la cadena láctea, ya que la participación de las unidades resulta más equilibrada, principalmente porque el flujo del producto en la cadena se determina con base en relaciones familiares y comunitarias (Hernández, Andablo y Ulloa, 2011). En las conclusiones, se complementan los resultados de la comparación con los de otras investigaciones sobre los corporativos que dominan el sistema agroalimentario globalizado y se enfatiza la necesidad de revalorar lo local y la necesidad de promover una política económica enfocada a fortalecer la integración de las familias rurales al sistema productivo en condiciones más equilibradas.

\section{GOBERNANZA EN LAS CADENAS DE VALOR}

Desde la perspectiva de Kaplinsky y Morris (2002, p. 4), las cadenas de valor "describen el amplio rango de actividades que se requieren para traer un produc- 
to o servicio desde su concepción, las diferentes fases de producción - que incluyen una combinación de transformaciones físicas, así como de varios servicios al productor-, hasta llegar a los consumidores finales y su disposición final después del uso". A partir de la internacionalización del capital, los encadenamientos trascienden las fronteras y se han vuelto complejos en la medida en que los productos pueden ser integrados en diferentes países y, sobre todo, consumidos lejos de su origen. En este sentido, el enfoque de cadenas de valor es útil para identificar la totalidad de los actores y procesos que intervienen en la generación de una mercancía. Gereffi y Korzeniewics (1994, p. 2) señalan que "una cadena global de mercancías consiste en un conjunto de redes interorganizacionales agrupadas en torno a una mercancía o producto, vinculando unidades familiares, empresas y estados en la economía mundial". Sin embargo, la descripción de la estructura de una cadena no es suficiente para ponderar la calidad de la participación de sus actores; para ello, se requiere profundizar en el análisis de estas redes o encadenamientos, por lo que se ha introducido la noción de gobernanza en el estudio de las cadenas de valor.

El concepto de gobernanza tiene diversas acepciones; Paz (2008, p. 195) observa que "el concepto es confuso pues es utilizado para referir [se] tanto [a] procesos de eficiencia administrativa como políticos. Así, desde ciertos enfoques, se privilegia la dimensión gerencial orientada hacia el mercado, la descentralización y el uso eficiente de los recursos públicos [...] mientras que desde otros, se enfatiza el carácter político ${ }^{3}$ y relacional del proceso".

El Programa de las Naciones Unidas para el Desarrollo (PNUD) revisa el concepto desde un enfoque de proceso y establece que la gobernanza comprende los complejos mecanismos, procesos, relaciones e instituciones a través de las cuales los ciudadanos y los grupos articulan sus intereses, ejercen sus derechos, obligaciones y median sus diferencias (UNDP, 1997). En síntesis, el concepto constituye, como señala Paz (2008), un marco analítico de las relaciones sociales y en términos generales puede definirse como propone Hufty $(2009$, p. 7): "los procesos de interacción entre los actores involucrados en asuntos colectivos que conducen a la toma de decisiones y la formulación de normas sociales". Se trata de diversos caminos que siguen los individuos y las instituciones públicas o privadas para manejar en conjunto sus intereses. Éste es un proceso continuo de

${ }^{3}$ Un caso ilustrativo de la aplicación de este concepto en el ámbito político se puede encontrar en el documento de la Unión Europea titulado "La gobernanza europea. Un libro blanco" (Madelin, 2001, p. 7). 
negociación, solución de conflictos y acomodo de diversos intereses, que establece un patrón de toma de decisiones en la interacción de los individuos y puede presentarse tanto en el ámbito de las relaciones formales con instituciones como en la informalidad.

Esta última acepción del concepto, que se refiere al proceso relacional de gestión de recursos es el que resulta útil para el análisis comparativo que se propone en el presente trabajo. Por ello, se ha tomado como referencia el análisis de la gobernanza en las cadenas de valor que realizaron Gereffi, Humphrey y Sturgeon (2005). Para estos autores, la gobernanza es el proceso en que los actores organizan sus actividades con el objetivo de alcanzar una cierta división del trabajo funcional a lo largo cadena, tomando decisiones en cuanto a la asignación de recursos a tareas específicas y en la distribución de los beneficios. En el contexto de una cadena, lo anterior implica el ajuste de los términos de integración de los socios, la incorporación/exclusión de otros actores y la reasignación de actividades que añaden valor (Gereffi, 1994, citado por Bolwig et al., 2010, p. 175).

Si bien, ésta constituye una visión gerencial y se enfoca al análisis de cadenas globales, la categorización que propone es muy apropiada para comparar la participación de los agentes en cualquier cadena de valor. Gereffi, Humphrey y Sturgeon $(2005$, p. 85) descomponen el concepto en tres variables: la complejidad de la información y de la transferencia de conocimiento requerida para llevar a cabo una transacción, en particular respecto al producto y las especificaciones del proceso; el grado al cual esta información y este conocimiento pueden ser codificados y, por lo tanto, transmitidos de manera eficiente entre los participantes, y las capacidades de los proveedores reales y potenciales en relación con los requerimientos de las transacciones. Con base en estos indicadores, define el grado de coordinación explícita y la asimetría de poder entre los actores de una cadena, refiriéndose el primer término a las formas de coordinación de la actividad económica que no están relacionadas con la dinámica de mercado, como el flujo de información entre los participantes y el conocimiento tácito requerido para interactuar en la cadena, entre otros elementos, mientras que el segundo denota principalmente la relación de dominio que se establece entre las firmas líderes y sus proveedores.

La dinámica de estos elementos determina en cada cadena el tipo de gobernanza que se ejerce entre sus integrantes. Así, "las firmas líderes incrementan la complejidad de las transacciones cuando sitúan nuevas demandas sobre la cadena de valor, tal como cuando buscan la oferta just-in-time y cuando incrementan la diferenciación del producto" (Gereffi, Humphrey y Sturgeon, 2005, p. 84). 
Este tipo de medidas reduce las posibilidades de entrada de nuevos competidores en la cadena, por lo que se fortalece la gobernanza de los proveedores frente a la firma líder.

El cuadro 1 muestra la tipología de cadenas que estos autores construyen con base en las variables señaladas. Los encadenamientos de mercado se caracterizan por un bajo nivel de complejidad en las transacciones, que son fácilmente codificadas; están basadas en el intercambio de productos estandarizados, en el que hay un alto nivel de competencia entre los proveedores y el costo de entrar o salir de la cadena es bajo para los participantes. Las cadenas de tipo modular son aquéllas en las que se producen mercancías según las especificaciones del consumidor; ello le confiere una alta especialización a los proveedores, o bien, capacidad de suministro. La gobernanza relacional se expresa entre los participantes de la cadena como su mutua dependencia; los intercambios se gestionan a través de la reputación o los vínculos familiares y étnicos entre proveedores y consumidores, lo que implica que existe un bajo nivel de codificación en las transacciones y una alta complejidad de éstas. Las cadenas cautivas se caracterizan por agrupar pequeños proveedores "transaccionalmente dependientes" de grandes compradores, con lo que generalmente se establece un elevado grado de monitoreo y control de los segundos sobre los primeros, determinando un alto nivel de codificación de las transacciones, pero una reducida capacidad para satisfacer la demanda de las firmas líderes en la cadena.

Cuadro 1. Determinantes claves de la gobernanza en las cadenas de valor.

\begin{tabular}{ccccc}
$\begin{array}{c}\text { Tipo de } \\
\text { gobernanza }\end{array}$ & $\begin{array}{c}\text { Complejidad } \\
\text { de las } \\
\text { transacciones }\end{array}$ & $\begin{array}{c}\text { Habilidad para } \\
\text { codificar las } \\
\text { transacciones }\end{array}$ & $\begin{array}{c}\text { Capacidad en } \\
\text { la base de } \\
\text { suministro }\end{array}$ & $\begin{array}{c}\text { Grado de coordinación } \\
\text { explícita y asimetría de } \\
\text { poder }\end{array}$ \\
\hline Mercado & Baja & Alta & Alta & Bajo \\
Modular & Alta & Alta & Alta & \\
Relacional & Alta & Baja & Alta & $\downarrow$ \\
Cautivo & Alta & Alta & Baja & Alto \\
Jerárquico & Alta & Baja & Baja & \\
\hline
\end{tabular}

Fuente: Tomado de Gereffi, Humphrey y Sturgeon (2005, p. 87).

Por último, el nivel jerárquico de gobernanza se refiere a la relación que se establece en corporativos integrados verticalmente, donde el control se ejerce de las casas matrices a las empresas subsidiarias o afiliadas. De esta forma, el nivel de gobernanza, expresado por el grado de coordinación explícita y la asi- 
metría de poder entre los participantes en una cadena, se mueve desde el extremo de los intercambios de mercado hacia las relaciones jerárquicas entre sus integrantes (Gereffi, Humphrey y Sturgeon, 2005).

\section{Metodología}

Para el análisis operativo, se construyó un concepto de gobernanza con base en las propuestas de Hufty (2009) y Gereffi, Humphrey y Sturgeon (2005). Ésta se definió como los procesos de interacción entre los actores involucrados en una cadena de valor que conducen a la toma de decisiones sobre la asignación de recursos y la distribución de los beneficios. Asimismo, tomando como referencia el ejercicio de Gereffi, Humphrey y Sturgeon, se determinaron tres variables para el análisis de las condiciones de integración de las URF de Cobachi a la cadena láctea y a la de carne de bovino. La primera se refiere a la complejidad de las transacciones, que conjunta lo que estos autores denominan la complejidad de la información necesaria para establecer las relaciones de intercambio en la cadena, así como el grado de codificación del proceso de intercambio, que en este caso se interpreta como el nivel de estandarización del producto, y la reproductibilidad del proceso de producción de las URF. Una segunda variable atiende a la capacidad de los participantes de las cadenas para cubrir la demanda de la siguiente fase de la circulación del producto. Por último, para el estudio de caso, se integró una tercera variable: una estimación de la participación en los ingresos generados en la cadena por parte de las URF y de otros actores que participan en ella en Sonora. En el cuadro 2 se presentan las variables y las categorías de análisis consideradas.

Para obtener la información de este estudio de caso se utilizaron entrevistas y seguimiento de las rutas de comercialización del queso. Los informantes fueron los integrantes de cinco URF de Cobachi y cinco queseros, agentes encargados del acopio del producto en la localidad; dos de ellos accedieron a ser acompañados en su ruta de distribución, con el fin de observar y registrar los detalles de la comercialización del queso fresco en Hermosillo, Sonora, capital del estado y principal plaza de venta, así como para identificar los 16 establecimientos comerciales que fueron visitados después para entrevista. También se entrevistó a tres intermediarios de becerro, agentes dedicados a realizar el acopio de los becerros en el ejido, uno de ellos a nivel local y dos para exportación o para la subasta de ganado que se realiza en la sede de la Unión Ganadera Regional de Sonora (UGRS), ubicada en Hermosillo. 
Cuadro 2. Descripción de variables y categorías de análisis consideradas para su definición operativa

\begin{tabular}{|c|c|c|}
\hline Variables & Categorías & Descripción \\
\hline \multirow{3}{*}{$\begin{array}{l}\text { Complejidad en } \\
\text { las transacciones }\end{array}$} & Tipo de relaciones & $\begin{array}{l}\text { Nivel de compromiso entre los actores; se refiere a } \\
\text { las relaciones sociales (de parentesco, fraternas, de } \\
\text { solidaridad y/o comunitarias), y económicas o de } \\
\text { mercado, establecidas entre las URF y otros actores } \\
\text { de la cadena. }\end{array}$ \\
\hline & $\begin{array}{l}\text { Características } \\
\text { del producto y } \\
\text { condiciones de } \\
\text { producción }\end{array}$ & $\begin{array}{l}\text { Forma en que se establecen las características del } \\
\text { producto y las condiciones de producción de las } \\
\text { URF participantes en cada cadena; especificidad del } \\
\text { producto y del proceso productivo. }\end{array}$ \\
\hline & $\begin{array}{l}\text { Establecimiento del } \\
\text { precio del producto }\end{array}$ & $\begin{array}{l}\text { Poder de negociación de las URF en la } \\
\text { determinación del precio del producto. }\end{array}$ \\
\hline \multirow{2}{*}{$\begin{array}{l}\text { Capacidad de } \\
\text { los proveedores } \\
\text { para cubrir la } \\
\text { demanda }\end{array}$} & $\begin{array}{l}\text { Recursos destinados } \\
\text { a la cadena }\end{array}$ & $\begin{array}{l}\text { Elementos de decisión que intervienen para } \\
\text { privilegiar el uso de los recursos productivos en } \\
\text { una u otra cadena en que participan las URF }\end{array}$ \\
\hline & $\begin{array}{l}\text { Representatividad } \\
\text { respecto a la } \\
\text { demanda }\end{array}$ & $\begin{array}{l}\text { Capacidad de las URF para cubrir la demanda del } \\
\text { mercado. }\end{array}$ \\
\hline \multicolumn{2}{|l|}{ Ingresos } & $\begin{array}{l}\text { Participación en los ingresos generados en cada } \\
\text { fase de la circulación de los productos de la } \\
\text { cadena. }\end{array}$ \\
\hline
\end{tabular}

Fuente: Elaboración propia con base en las variables de gobernanza desarrolladas por Gereffi, Humphrey y Sturgeon (2005).

\section{INTEGRACIÓN DE LAS URF DEL EJIDO COBACHI A LAS CADENAS PECUARIAS}

En Sonora, las URF practican una ganadería de pequeña escala -con treinta vientres o menos ${ }^{4}$ por productor-, se sostienen con trabajo familiar, utilizan conocimientos transmitidos de generación en generación, practican estrategias de cooperación y combinan la producción pecuaria con otras actividades desarrolladas dentro y fuera de la comunidad. En la crianza de ganado también emplean modelos tecnológicos extensivos y de bajo nivel. En 2009, los productores con treinta vientres o menos representaron $69.8 \%$ del padrón de ganaderos y concentraron $39.1 \%$ del inventario ganadero estatal. En particular, el distrito de desarrollo ru-

${ }^{4}$ Diversos estudios sobre la ganadería a pequeña escala en Sonora consideran que ésta se ubica en el estrato de treinta vientres o menos (Hernández y Camou, 1994; Camou, 1998). 
$\mathrm{ral}^{5}$ (DDR) de Mazatán, donde se ubica el ejido Cobachi (figura 1), abarcó 8.1\% de criadores a esta escala. En Cobachi, los ganaderos con treinta vientres o menos son $72.1 \%$. El ejido cuenta con 12310 hectáreas, de las cuales $11.7 \%$ están parceladas; sólo $2.4 \%$ de la superficie ejidal cuenta con riego. En 2008, 80.6\% de los ejidatarios con parcela disponía de treinta hectáreas o menos, destinadas principalmente a la alimentación del ganado, incluyendo las tierras de riego localizadas a la vera del río Mátape, principal afluente del ejido, cuyas aguas subterráneas se utilizan para la siembra de forrajes.

Figura 1. Ubicación del ejido Cobachi

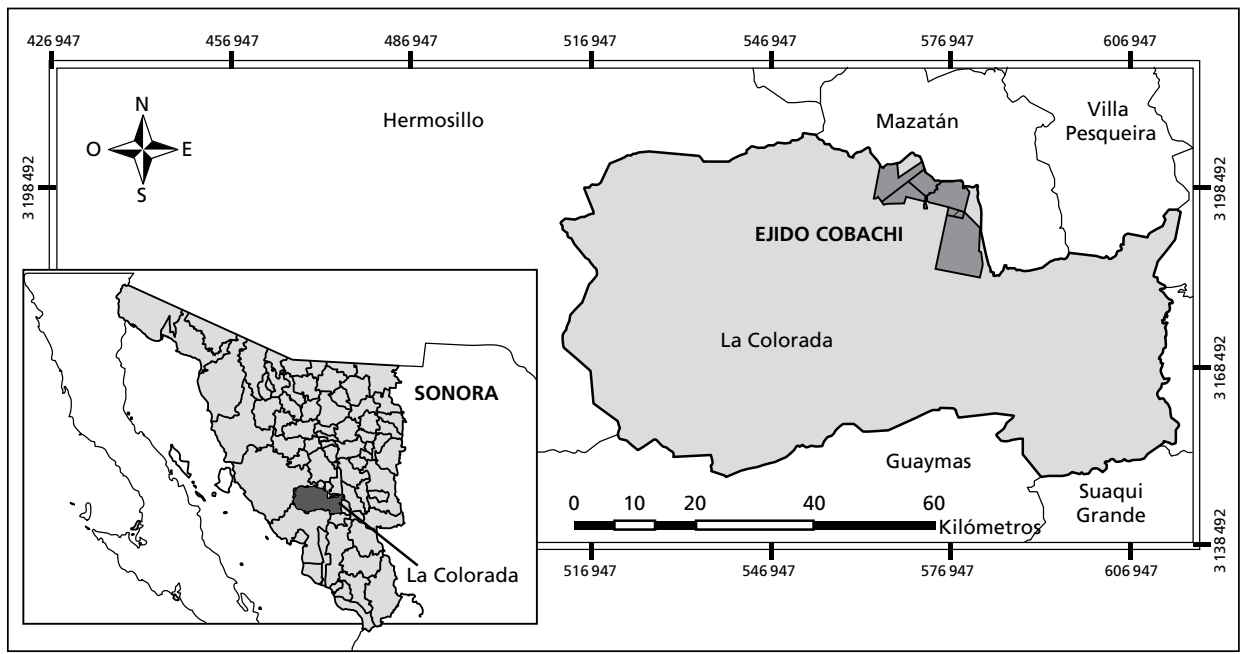

Fuente: Elaboración propia con base en cartas topográficas del Instituto Nacional de Geografía e Informática mediante el programa ArcGis 9.3. Escala: 1:50 000 y 1:250 000. Polígono del ejido Cobachi. Sistema de Coordenadas Universal Transversal de Mercator (UTM), zona 12, datum WGS 84 .

Si bien la vocación ganadera de estas familias se remonta a la colonización española de la región durante el siglo XVII, su integración a la cadena de producción cárnica comenzó a fines de los años cincuenta, con la sustitución del ganado criollo por razas europeas especializadas en producción de carne (Camou, 1998). Este proceso se inició a raíz de la influencia que ejerció la internacionalización del modelo estadounidense de engorda industrial y se consolidó en

${ }^{5}$ Los DDR son el criterio de regionalización de la Secretaría de Agricultura, Ganadería, Pesca y Desarrollo Rural (SAGARPa). Este criterio de organización de los municipios se realizó con base en características socioeconómicas homogéneas para la agricultura y prevalece desde 1987. 
los sesenta con el proceso de "ganaderización" inducido desde el Estado, con políticas de fomento como el Programa Nacional de Ganaderización, la Comisión Nacional de Desmontes y los Programas de Inversiones Públicas para el Desarrollo Rural (Bravo et al., 2010). De esta forma, las URF sonorenses participan en una compleja cadena de producción y distribución, caracterizada por una base social heterogénea y geográficamente dispersa (Hernández y Camou, 1994), con eslabones locales, nacionales y, sobre todo, en EU, cuya industria cárnica absorbe $61 \%$ de la producción sonorense de becerros (Hernández, Andablo y Ulloa, 2011, p. 64), que es comandada por las corporaciones estadounidenses a nivel global. En ese contexto, las familias rurales se integraron en condiciones desiguales a competir con los grandes corporativos por el valor agregado generado en la cadena. Desde entonces, éstos han definido, a través de una red nacional de intermediarios, la dinámica y condiciones de producción en Sonora.

En contraste, las URF también participan en una cadena de lácteos a nivel local, a la que se integran como productoras de queso fresco. En este caso, su participación resulta más equilibrada, principalmente porque el flujo de este bien en la cadena se determina con base en relaciones familiares y comunitarias (Hernández, Andablo y Ulloa, 2011).

En la producción quesera, los saberes sobre su elaboración también constituyen una herencia colonial, sin embargo, el desarrollo de la comercialización del queso estuvo vinculado a hechos locales y regionales: el reparto agrario, concentrado entre 1930 y 1950 en los municipios del DDR de Mazatán, permitió el acceso a recursos agropecuarios; la urbanización de Hermosillo les brindó una plaza comercial con demanda suficiente y la posibilidad de extender sus redes sociales y familiares, y el desarrollo carretero en los ochenta, que constituyó un elemento clave para el fortalecimiento del circuito comercial del queso, consolidó una ruta de distribución que ya existía desde los años cuarenta (Andablo y Hernández, 2011). Estos elementos incidieron en que la cadena de lácteos se desarrollara a través de las estrategias de las familias rurales, a diferencia de la cría de becerro, en la que la política estatal constituyó el principal detonante de la actividad.

La cadena de lácteos consta de sólo dos eslabones: en el primero se fusionan el proceso de producción primaria y su transformación/industrialización, y en el segundo se realiza la distribución hasta el consumo final. Esta circunstancia facilita el tránsito del producto, pero también es reflejo de que las familias no se han enfocado en potenciar la actividad mediante la diversificación de sus productos y la exploración de nuevos mercados. 


\section{La gobernanza en la cadena de lácteos}

La dinámica productiva de Cobachi gira en torno a la ganadería, los productores trabajan en ranchos, donde conviven integrantes de una o varias URF que generalmente forman parte de una familia extensa: padres, hijos, cuñados, primos y otros parientes. La elaboración del queso es artesanal y con base en las prácticas tradicionales heredadas de generación en generación. Las tareas cotidianas se dividen de la siguiente forma: los varones se dedican al cuidado del ganado, la ordeña y la hechura de la cuajada, actividades que realizan en los ranchos que están ubicados de manera dispersa en el territorio del ejido. Es frecuente que en la división interna del trabajo las mujeres se encarguen de la elaboración de los quesos en la vivienda ubicada en la comunidad, para lo cual utilizan la cuajada que reciben diariamente de los varones.

Los eslabones primario y de transformación están concentrados por las URF, e incluso algunos integrantes de las unidades intervienen directamente en la comercialización del producto, tanto en etapas intermedias como en la venta al consumidor final. Se trata de una cadena dominada por las relaciones personales y familiares. La circulación del producto se inicia con la entrega al quesero, quien también distribuye el que produce en su propia unidad familiar.

Los queseros concentran la producción de Cobachi y trasladan el producto dos veces por semana a la ciudad de Hermosillo, a hora y media de camino. En la ciudad, distribuyen los quesos en tiendas de abarrotes locales ubicadas en colonias populares, o bien, lo comercializan directamente en casas o tiendas que pertenecen a la propia familia. Ocasionalmente, una parte del producto también se exporta a EU mediante redes familiares, que a su vez lo distribuyen entre paisanos que lo buscan como producto de nostalgia (Cruz, López y Schatan, 2004).

Entre los queseros y las familias proveedoras existe una relación estrecha y en ocasiones pertenecen a la misma familia extensa. Esta relación se fortalece a través de la dinámica de intercambio, ya que en cada viaje que realiza a Hermosillo, se abastece de productos de consumo familiar y de insumos productivos que a su vez suministra a sus proveedores. En la segunda fase de la circulación del producto, que se realiza en la ciudad, prevalece también una relación personal entre proveedores y compradores. Estos últimos pueden ser establecimientos comerciales en colonias populares, o bien, consumidores finales. En la mayoría de los casos, el intercambio se fundamenta en vínculos familiares o de amistad, lo que garantiza una demanda segura del producto incluso en tiempos de sobreoferta. Estos estrechos vínculos entre los participantes de la cadena, que 
van más allá de la relación económica, facilitan la negociación de intercambio. Desde la perspectiva de Gereffi, Humphrey y Sturgeon (2005), la gobernanza que se desarrolla en cadenas que funcionan en estas condiciones es de tipo relacional, como se corrobora en los resultados que se presentan enseguida.

Para estudiar el caso de la cadena de lácteos se dio seguimiento a la actividad de dos queseros de los diez que operan en Cobachi. Estos dos agentes concentran la oferta de $12 \mathrm{URF}$, incluyendo la propia, lo que significa que atienden la cuarta parte de un total de 48 unidades familiares productoras de queso, de las cuales 23 comercializan directamente su producto en Hermosillo. Como se señaló en el apartado metodológico, para definir la primera variable, complejidad de las transacciones, se consideraron tres aspectos: el tipo de relaciones, las características del producto y de las condiciones de producción y el establecimiento del precio.

En cuanto al primer aspecto, las relaciones socioeconómicas en esta cadena son dominadas por los vínculos familiares y de amistad. Esta característica no sólo se circunscribe a la comunidad, sino que se reproduce en el proceso de comercialización del queso en Hermosillo. En Cobachi, una comunidad de noventa viviendas habitadas, es común que existan estrechos lazos familiares o de amistad entre sus pobladores, por lo que las URF forman redes que propician una distribución más generalizada de los ingresos que se generan en esta cadena.

El primer quesero, a quien se identificará como "quesero A", distribuye el producto de seis URF, además del propio, y se dedica a esta actividad desde hace más de veinte años; algunos de sus proveedores lo han sido desde entonces y entre ellos se encuentra su propio hijo, quien se independizó hace cuatro años. El segundo distribuidor, "quesero B", acopia la producción de tres unidades familiares, además de la suya, y hace diez años que inició esta actividad, si bien no tiene vínculos familiares, declara que sostiene amistad con sus proveedores. En los acuerdos comerciales entre estos actores también se dan situaciones como intercambios en especie (queso por mercancías que los intermediarios llevan de la ciudad a la comunidad), préstamos de reses para la ordeña, o bien, relaciones de compadrazgo que comprometen a los queseros y determinan una mejor posición para la URF proveedora.

Los queseros llevan el producto a Hermosillo dos veces por semana y entre ambos abastecen a 16 comercios. Al igual que con las URF, la relación con los comerciantes o abarroteros se establece mediada por vínculos de amistad, directos cuando son amistades de algún familiar del quesero, y/o indirectos, por coincidencias regionales, como provenir de pueblos cercanos o conocer Cobachi 
por alguna circunstancia personal. Esta interacción se fortalece sobre todo por la antigüedad de la relación comercial, ya que esto contribuye a incrementar la confianza entre ellos. En los cuadros 3 y 4, se observa que para ambos queseros, la relación con la mayor parte de sus clientes es de tres años o más. De esta forma, pueden establecer tratos especiales, dependiendo de la situación y de sus necesidades, incluyendo tratos solidarios como el que testimonió uno de los comerciantes entrevistados, a quien, después de un asalto a su establecimiento, el quesero B siguió surtiendo sin cobrar hasta que recuperó su estabilidad económica.

Cuadro 3. Ruta de comercialización del quesero A

\begin{tabular}{cccccccc}
\hline $\begin{array}{c}\text { Tienda } \\
\text { de } \\
\text { abarrotes }\end{array}$ & $\begin{array}{c}\text { Tiempo de } \\
\text { relación } \\
\text { comercial } \\
\text { (años) }\end{array}$ & $\begin{array}{c}\text { Tipo de } \\
\text { relación }\end{array}$ & $\begin{array}{c}\text { Proveedor } \\
\text { único } \\
\text { (sí/no) }\end{array}$ & $\begin{array}{c}\text { Precio de } \\
\text { compra } \\
\text { (pesos } \\
\text { mexicanos } \\
\text { por kg) }\end{array}$ & $\begin{array}{c}\text { Precio de } \\
\text { venta } \\
\text { (pesos } \\
\text { mexicanos } \\
\text { por kg) }\end{array}$ & $\begin{array}{c}\text { Cantidad } \\
\text { recibida } \\
\text { (kg) }\end{array}$ & $\begin{array}{c}\text { Entregas } \\
\text { semanales }\end{array}$ \\
\hline A1 & 1 & Comercial & Sí & 37 & 45 & 15 & 1 \\
A2 & 3 & Comercial & Sí & 37 & 45 & 20 & 2 \\
A3 & 8 & Amistad & Sí & 37 & 48 & 15 & 2 \\
A4 & 20 & Comercial & Sí & 37 & 47 & 16 & 2 \\
A5 & 8 & Comercial & Sí & 37 & 45 & 24 & 2 \\
A6 & 1.5 & Amistad & Sí & 37 & 48 & 9 & 2 \\
A7 & 4 & Amistad & No & 35 & 45 & 7 & 1 \\
A8 & 12 & $\begin{array}{c}\text { Origen } \\
\text { rural }\end{array}$ & Sí & 37 & 42 & 15 & 2 \\
A9 & 10 & Comercial & Sí & 38 & 48 & 15 & 2 \\
\hline
\end{tabular}

aValores correspondientes a una sola entrega.

Fuente: Elaboración propia con base en entrevistas (julio de 2011).

Un tercer productor y distribuidor de queso de Cobachi declaró en la entrevista que estaba iniciándose en la actividad, ya que su padre había fallecido recientemente y él había decidido hacerse cargo de su red de distribución. En este sentido, se puede señalar que las relaciones de confianza logradas por un quesero benefician a la familia de éste, al grado que la cartera de clientes y proveedores puede ser heredada a sus parientes.

Las relaciones descritas arriba confirman la existencia de una estrecha dependencia entre los actores de la cadena, que condiciona la dinámica del intercambio y muestra una flexibilidad de transacciones que se ajusta a las circunstancias y necesidades de proveedores y comerciantes. Gereffi, Humphrey y 
Sturgeon $(2005$, p. 86$)$ señalan que las transacciones en la cadena relacional se caracterizan por esta mutua dependencia entre los participantes, la cual es regulada a través de la reputación y los lazos familiares. Asimismo, enfatiza el rol de la proximidad espacial en el desarrollo de esta clase de cadenas, aunque subraya que dichas confianza y reputación también funcionan en redes dispersas cuando las relaciones son construidas a través del tiempo, o bien, se trata de grupos sociales o familias con fuertes vínculos.

Cuadro 4. Ruta de comercialización del quesero B

\begin{tabular}{cccccccc}
\hline $\begin{array}{c}\text { Tienda } \\
\text { de } \\
\text { abarrotes }\end{array}$ & $\begin{array}{c}\text { Tiempo de } \\
\text { relación } \\
\text { comercial } \\
\text { (años) }\end{array}$ & $\begin{array}{c}\text { Tipo de } \\
\text { relación }\end{array}$ & $\begin{array}{c}\text { Proveedor } \\
\text { único } \\
\text { (sí/no) }\end{array}$ & $\begin{array}{c}\text { Precio de } \\
\text { compra } \\
\text { (pesos } \\
\text { mexicanos } \\
\text { por kg) }\end{array}$ & $\begin{array}{c}\text { Precio de } \\
\text { venta } \\
\text { (pesos } \\
\text { mexicanos } \\
\text { por kg) }\end{array}$ & $\begin{array}{c}\text { Cantidad } \\
\text { recibidaa } \\
\text { (kg) }\end{array}$ & $\begin{array}{c}\text { Entregas } \\
\text { semanales }\end{array}$ \\
\hline B1 & 9 & Familiar & Sí & 35 & 48 & 12 & 2 \\
\hline B2 & 1.5 & Comercial & Sí & 35 & 48 & 7 & 2 \\
B3 & 5 & Comercial & No & 35 & 50 & 25 & 2 \\
B4 & 3 & Comercial & Sí & 35 & 50 & 10 & 2 \\
B5 & 3 & Comercial & Sí & 35 & 50 & 5 & 1 \\
\hline B6 & 3 & Comercial & No & 35 & 40 & 11 & 1 \\
\hline B7 & 8 & Amistad & No & 34 & 45 & 10 & 1 \\
\hline
\end{tabular}

aValores correspondientes a una sola entrega.

Fuente: Elaboración propia con base en entrevistas (julio de 2011).

Un segundo factor considerado son las características del bien y sus condiciones de producción. En este caso se trata de un producto artesanal que se diferencia de los industrializados que se ofrecen en las cadenas comerciales de la capital. El principal elemento que define su carácter artesanal es el hecho de que no hay un proceso estandarizado de elaboración y que se realiza en pequeña escala; incluso el queso que produce cada URF tiene diferentes características y cada familia está orgullosa de que su producto sea preferido sobre otros. De esa forma, el queso fresco tiene un mercado delimitado y consolidado entre los habitantes de Hermosillo con al menos setenta años de antigüedad. Los comerciantes detallistas también comparten esta preferencia, la cual se fortalece por el origen rural. Estos elementos de identidad le confieren al producto ventaja en el mercado respecto a los quesos industriales, de tal forma que garantiza una estabilidad en la demanda que beneficia a todos los actores de la cadena: URF, queseros y 
abarroteros. Dichas condiciones les permiten sobrellevar las fluctuaciones de la oferta que cada año se presentan: alta producción y bajo precio en el verano, y escasez y al alto precio en el invierno.

La calidad cíclica de la ordeña es un factor exógeno que influye en la determinación del precio del queso durante el año. Durante la época de lluvias, que en esta región transcurre de finales de junio hasta agosto, la producción se incrementa por la abundancia de pastos, lo que en ocasiones dificulta que los queseros coloquen el producto, debido a la sobreoferta; sin embargo, la fortaleza de la relación con sus clientes es determinante para sobrellevar este periodo sin verse perjudicados y sin que, a su vez, bajen demasiado los precios a las URF proveedoras. La principal ventaja de los queseros en este caso es el hecho de que la mayoría constituyen proveedores únicos de los comercios de Hermosillo. En el caso de las rutas comerciales de los queseros A y B, se encontró que para $69 \%$ de sus clientes son proveedores únicos, lo que los posiciona en una situación ventajosa en los periodos críticos de la actividad. Sin embargo, esta misma circunstancia constituye una ventaja para el abarrotero en época de escasez, ya que su compromiso con el quesero en la época de lluvias le garantiza la disponibilidad del producto en el invierno, cuando disminuye la producción en toda la región quesera. ${ }^{6}$

En relación a la segunda variable, la capacidad de los productores para cubrir la demanda del mercado, se consideraron, primero, los factores que determinan la toma de decisiones en la URF sobre los recursos destinados a la quesería en relación con los destinados a la cría de becerro y, en segundo lugar, la representatividad respecto a la demanda.

En lo que toca al primer aspecto, destaca el hecho de que la quesería está subordinada a la cría de becerros. Esto se constata en que el ganado es predominantemente de carne, de razas como brahma, charolais, angus, aunque en las últimas décadas se han introducido sementales de doble propósito, como los simmental. A pesar de que la ordeña es la principal fuente de ingresos cotidianos de las URF, éstas organizan la producción en torno al becerro. En este sentido, toman decisiones como la siguiente: desde julio, recién iniciadas las lluvias, hasta el mes de octubre, cuando se realiza la venta de becerros, dejan de ordeñar a las vacas con becerros machos, con el fin de que éstos se alimenten libremente y ganen peso en el agostadero o en las praderas (Andablo y Hernández, 2011). Según datos recabados en campo, lo anterior significa que durante esos cuatro me-

${ }^{6}$ La región quesera centro abarca 12 localidades que surten a la ciudad de Hermosillo (Andablo y Hernández, 2011). 
ses los criadores dejan de ganar la producción lechera de siete vacas, lo que asciende a MXN $18900 .^{7}$

Para estimar la capacidad para cubrir la demanda, se obtuvieron datos de la cantidad de mercancía entregada por las URF a los queseros. Según la información proporcionada al momento de la entrevista (julio de 2011), el quesero A recibía un promedio de $4 \mathrm{~kg}$ diarios de cada uno de sus siete proveedores, mientras que el quesero B recibía $5 \mathrm{~kg}$ al día de sus tres proveedores. A estas cantidades se agrega lo producido por cada quesero. En total, A estaba recibiendo entre $260 \mathrm{y}$ $300 \mathrm{~kg}$ a la semana y B entre 160 y $200 \mathrm{~kg}$, lo que significa que cada URF proveedora representaba en promedio $11 \%$ de las existencias semanales de A y $22 \%$ de las de B. Así, en ambos casos, es posible afirmar que para los queseros es importante conservar a sus proveedores porque les aportan cantidades significativas de su oferta, sobre todo considerando que siempre existe la posibilidad de que las URF entreguen su mercancía a otro quesero o decidan comercializarla de manera independiente, como hace casi la mitad de las familias.

Por otra parte, para identificar la ruta de comercialización de cada intermediario, se acompañó a cada uno en la distribución del producto. En verano, época en que se realizó el estudio de caso, los queseros empiezan muy temprano por la mañana para evitar la merma del producto por el calor, ya que pueden perder hasta $10 \%$ del queso por esta causa, de modo que hacia medio día han terminado su ruta. Una estrategia para disminuir el tiempo de entrega es que cada quesero concentra sus clientes en una zona. En los cuadros 3 y 4 se presenta un resumen de los principales resultados del seguimiento de cada ruta.

Como se observa en los cuadros, la cantidad entregada es variable y depende de las necesidades de cada tienda de abarrotes. Si bien el precio del producto se define en función de las condiciones de oferta y demanda prevalecientes en el mercado local, según el comportamiento cíclico de la producción descrito, generalmente los pequeños comerciantes aceptan el precio determinado por el quesero. Aunque en esta aceptación influye la fortaleza de los vínculos establecidos entre los actores, como se apunta en la explicación del tipo de relaciones en la cadena, esta ventaja se deriva también en gran medida del hecho de que en la mayor parte de los casos son proveedores únicos, por lo que cubren $100 \%$ de su demanda de quesos. Por ello, la situación cambia en los comercios donde deben competir con otros proveedores de queso. Uno de los productores que entrega

\footnotetext{
${ }^{7}$ Considerando la producción de siete vacas, que equivale a $7 \mathrm{~kg}$ de queso diarios durante cien días y al precio declarado por los queseros en julio de 2011, de MXN 27 por kilogramo.
} 
directamente su queso a dos establecimientos, uno perteneciente a su familia y otro con el que sólo tiene una relación comercial, señala que en el segundo debe ceder en la determinación del precio, ya que compite con otros dos queseros, y en tiempos de sobreoferta tiene que bajar su precio a un nivel que el abarrotero considere conveniente para no perder la entrega. En este sentido, para los queseros resulta más conveniente permanecer vinculados a las redes familiares para garantizar el carácter relacional de sus transacciones, como sostienen Gereffi, Humphrey y Sturgeon (2005). Esta circunstancia se confirma también por el hecho de que 13 de las 48 familias $^{8}$ productoras de queso de Cobachi han optado por comercializar directamente su producto, ya sea en tiendas de abarrotes, en domicilios propios o mediante algún familiar en Hermosillo.

En términos de los ingresos generados, solo fue posible estimar la proporción del ingreso que retienen los actores en cada fase de la circulación. El quesero A incrementa en $32 \%$ el precio respecto a la cantidad pagada a cada URF, mientras que el quesero B sólo lo hace en $29 \%$. A su vez, los comerciantes de Hermosillo que reciben queso de A incrementan $24 \%$ el precio, en promedio, mientras aquellos que lo adquieren con B, lo hacen en 36\%. Por otra parte, en términos de la proporción del precio final del producto, se estima que en el caso de A, las URF retienen $61 \%$, el quesero $20 \%$ y el comerciante $19 \%$, en promedio, mientras que en el caso de B, las URF se quedan con 57\%, el quesero con $17 \%$ y los comerciantes con $26 \%$. Si bien esta evaluación coloca a los queseros en una posición de intermediación por la que retienen casi la quinta parte del valor final del producto, es importante señalar que éstos también forman parte de las unidades familiares de Cobachi, por lo que los beneficios obtenidos se quedan en la misma comunidad y constituyen el canal para fortalecer la posición de sus URF proveedoras. Asimismo, es importante señalar que las familias que distribuyen directamente su producto se quedan en promedio con $80 \%$ del precio al que lo expenden las tiendas de abarrotes, o bien, con $100 \%$ cuando lo venden directamente al consumidor final.

\section{La gobernanza en la cadena de carne de bovino}

Las URF se integran a la cadena de carne de bovino a través de una red de intermediarios. Hernández y Camou (1994) realizaron un análisis detallado del surgimiento y consolidación del intermediarismo en Sonora; ubican el inicio de esta

\footnotetext{
${ }^{8}$ Sin contar las familias de los diez queseros que operan en el ejido.
} 
actividad a mediados de los cincuenta con "la incorporación masiva de los pequeños criadores de becerro" a la cadena de cárnicos de EU, de acuerdo con Hernández y Camou (1994, p. 168). Estos autores identifican cuatro fases en el proceso de producción de la carne, relacionadas con la disponibilidad de recursos de los agentes involucrados: cría, preengorda, engorda, y sacrificio y clasificación. En el caso particular de la producción de becerros integrada a la industria cárnica estadounidense, las primeras dos fases se desarrollan en territorio sonorense, mientras que las últimas dos se llevan a cabo principalmente al norte de la frontera mexicana.

La participación de las URF se concentra principalmente en la fase de cría, porque sus limitados recursos productivos no les permitieron, desde su integración a la cadena, participar en las fases posteriores. Esto marcó un proceso de especialización de estas unidades familiares que se ha consolidado con el desarrollo de la industria cárnica de EU. Particularmente, la fase de preengorda, con una fuerte presencia de intermediarios, constituyó el eslabón que integró a los criadores de becerro a la cadena de carne de bovino, pero también representó el mecanismo de imposición de las necesidades de demanda de la industria cárnica estadounidense sobre las condiciones de producción de las URF sonorenses. De esta forma, desde mediados de los cincuenta se inició un proceso de encastamiento del hato ganadero dirigido a sustituir las razas criollas, que fueron introducidas por los españoles y adaptadas durante varios siglos a las condiciones regionales, por razas europeas orientadas a la producción de carne (Pérez, 1993).

El papel del intermediario se limita a retener el menor tiempo posible el producto para estabilizarlo o estandarizarlo: castrar los becerros, resolver algún problema de salud, o bien, acopiar una carga completa. En este sentido, el principal objetivo del intermediarismo en la fase de circulación sigue siendo el mismo que le dio origen: concentrar una oferta dispersa y atomizada en Sonora (Hernández y Camou, 1994, p. 181). Por otra parte, en esta fase de circulación participan intermediarios de distintos ámbitos de acción, como concentradores o como exportadores, o que atienden distintas escalas geográficas de acopio: local, regional o transregional (Hernández y Ulloa, 2000, p. 73). ${ }^{9}$ En contacto directo

\footnotetext{
${ }^{9}$ Con el fin de sistematizar la riqueza en las formas de participación de los intermediarios en la red de distribución de los becerros que van a la industria cárnica estadounidense, en este trabajo se propuso una tipología. Un primer elemento para diferenciar a los intermediarios fue su función de "enlace", es decir, si el intermediario vincula a otros agentes o unidades de producción dentro de Sonora, se le denominó comisionista; si el intermediario enlaza a un agente o unidad de producción situados en territorio mexicano con otro agente o unidad de producción de EU, se le identificó
} 
con los productores, están los intermediarios locales o "coyotes", que cumplen la tarea de recolectar la oferta dispersa en uno o varias comunidades; posteriormente, los becerros reunidos son entregados a otro intermediario de mayor escala que acopia ganado de distintos municipios para luego exportarlos, o bien, son llevados directamente a Hermosillo, para ser vendidos en la subasta de la UGRS, que constituye el principal referente para el establecimiento del precio por kilogramo de becerro. A esta plaza acuden también intermediarios que compran ganado para exportación.

En el caso particular de Cobachi, hay un intermediario local que acopia parte de la oferta ejidal de becerros, pero acuden al menos otros dos intermediarios de mayor escala cuando son convocados por los productores. Normalmente, las URF tienen dos meses de entrega de ganado al año, marzo y octubre, aunque pueden realizar ventas a destiempo, dependiendo de sus necesidades: gastos médicos, fiestas familiares o tradicionales, inicio o término del ciclo escolar, así como eventos climáticos que rompen el frágil equilibrio financiero de estas unidades de producción-consumo. Desde su nacimiento, la figura del intermediario ha desempeñado varias funciones en la cadena: fungir como enlace entre los ganaderos de pequeña escala y la industria de engorda, ser el mecanismo de transmisión de las condiciones de demanda de esta industria y, a nivel local, desempeñar un papel como agente financiero para las URF, que por su tamaño no pueden acceder a fuentes de financiamiento formales (Hernández y Camou, 1994).

Este dinámico papel de los intermediarios, en combinación con la fragilidad económica de las unidades familiares, ha favorecido el desarrollo de una estrecha dependencia de éstas respecto a los primeros. En otros términos, estos agentes acopiadores ejercen un fuerte control sobre el proceso productivo local. Sin embargo, son sólo los transmisores del control que, en realidad, se origina en la industria estadounidense, en la que se definen las características de la demanda y a las cuales se subordinan todos los agentes participantes de la cadena en Sonora.

Desde la perspectiva de Gereffi, Humphrey y Sturgeon (2005, p. 86), la dinámica de gobernanza que se desarrolla en estas cadenas es de tipo cautivo: "En estas redes, los pequeños proveedores son transaccionalmente dependientes de los grandes compradores [...] Tales redes frecuentemente están caracterizadas

como exportador. A, su vez, los comisionistas fueron clasificados por ámbito de acción: locales, regionales y transregionales; a los exportadores se les separó en función del volumen de becerros exportado. Si se desea profundizar en esta información, véase Hernández y Ulloa (2000). 
por un alto grado de monitoreo y control por parte de las empresas líderes". Con base en la información de campo y otros datos de fuentes indirectas, se tratará de demostrar que en la cadena de carne de bovino se desarrolla este tipo de gobernanza.

Respecto al primer aspecto de la complejidad de las transacciones, el tipo de relaciones, se encontró que en Cobachi se establecen relaciones socioeconómicas de dependencia unilateral de las URF respecto a los intermediarios, que se definen por la dinámica de financiamiento anual. Cada año las unidades familiares requieren financiamiento para sobrellevar los meses de sequía, desde marzo a julio; en este periodo, que puede extenderse si no se presentan lluvias en diciembre o se retrasan las de julio, los ganaderos necesitan comprar suplementos alimenticios para el ganado que les permitan sostener la ordeña. En Cobachi, existen básicamente dos opciones: los servicios financieros del Grupo Empresarial de Negocios, SA (GRENSA), ${ }^{10}$ con los correspondientes trámites en Hermosillo para ser sujetos de crédito y las condiciones inflexibles para su liquidación, o bien, solicitar crédito a los intermediarios, a cuenta de animales.

En particular, el intermediario local de Cobachi tiene 15 años desempeñando esta función; es ejidatario, vive en la comunidad y forma parte, a su vez, de una URF quesera. En este sentido, las relaciones con este actor suelen ser más flexibles y solidarias que las establecidas con los intermediarios externos a la comunidad o las instituciones financieras. Este intermediario, al que se le denominará "don J" presta a la palabra a los criadores, quienes en virtud de este trato quedan como proveedores cautivos, ya que comprometen la venta de sus becerros o de otros animales. Don J recibe toda clase de ganado: vaquillas, toros o vacas, y de todas las razas: angus, cimbra, simmental, brangus, charolais; acopia el ganado sólo dos días y luego lo entrega a otro intermediario en el municipio de Mazatán, que se encuentra a media hora de camino. Don J considera que no es conveniente conservar más tiempo el ganado porque debe invertir en alimento (entrevista, julio de 2011).

Alguna vez intentó llevar el ganado directamente a la subasta en la UGRS, sin embargo, no le resultó conveniente, porque los precios son arbitrarios, existe el riesgo de que los animales se enfermen por el viaje y, particularmente, porque el ganado se clasifica de manera unilateral. En dicha subasta, los becerros se clasifican por números: 1 (raza pura), 11/2 (cruza con alta genética de carne) y 2 (baja genética de carne); este último se asigna generalmente a los becerros de ganado

\footnotetext{
${ }^{10}$ Opera en Hermosillo, Sonora, a través del Banco del Bajío.
} 
lechero: holstein, suizo, jersey, entre otras razas. En uno de los viajes a la subasta, don J llevó 17 becerros, de los cuales 16 fueron clasificados como 11/2 y uno de ellos, el más pesado, como 2, lo que significó la pérdida total de las ganancias del viaje, en vista de que el precio del tipo 2 es, en promedio, la mitad del precio del 11/2. ${ }^{11}$ La inconveniencia de los viajes de don J está relacionada directamente con el tamaño del hato que logra acopiar localmente; por esta razón, le resulta más redituable entregar sus becerros a un intermediario regional que tiene mayor capacidad de negociación y para enfrentar pérdidas circunstanciales como la señalada. De esta forma, la dependencia que se genera entre las URF respecto a los intermediarios locales se reproduce en la siguiente fase de la circulación, entre los "coyotes" y los intermediarios regionales y/o los exportadores de becerro.

Las características deseables del producto, en este caso el becerro, son determinadas por los intermediarios, quienes constituyen los transmisores de los requerimientos de la industria estadounidense en Sonora. Particularmente, la clasificación descrita arriba constituye una de las principales formas de control sobre la cría de becerros en Sonora: a ella se sujetan no sólo las URF de Cobachi, sino todo productor de becerros -ya sea empresarial o doméstico- de México que pretenda vender su ganado a la industria estadounidense. Gereffi, Humphrey y Sturgeon $(2005$, p. 87) señalan que en una cadena cautiva, las empresas líderes definen la dinámica productiva de las proveedoras, además de que estas últimas frecuentemente se limitan a un estrecho rango de tareas. En este caso, las URF asumen la etapa más crítica de la producción de la carne, es decir, la cría; esto es así debido a que la vida del animal aún es frágil y la generación de valor agregado es limitada.

Los intermediarios consultados señalaron que en Cobachi reciben los becerros con un peso promedio de $180 \mathrm{~kg}$. Si bien reciben cualquier peso y raza, éstos condicionan el precio pagado, ya que si el animal rebasa la barrera de los $180 \mathrm{~kg}$ aplican una tasa de descuento que castiga el precio con 50 centavos por cada kilogramo excedido. Esta práctica se reproduce entre los intermediarios y los brokers $^{12}$ en la frontera, donde el límite son $272 \mathrm{~kg}$, o bien, 600 libras. Asi-

\footnotetext{
${ }^{11}$ A manera de ejemplo, se puede citar los precios establecidos en la subasta del 3 de julio de 2012. La tabla publicada indica que el becerro tipo 1 se pagó a MXN 50.20 por kilogramo, el $1 \frac{1 / 2}{2}$ a MXN 47.00 y el 2 a MXN 27.80. Los precios pueden variar en cada subasta; particularmente, en este ejemplo, reflejan una coyuntura de incremento del precio del becerro, pero aun así la diferencia es significativa. Datos de la UGRS (s.f.).

${ }^{12}$ Intermediarios que concentran la producción de becerros en la frontera para venderlos a los engordadores en los Estados Unidos (Hernández y Ulloa, 2000).
} 
mismo, el castigo al precio se relaciona con la salud del animal y la raza; en la frontera sólo se reciben becerros de razas productoras de carne, mientras que el ganado holstein, suizo o jersey se destina al mercado interno. La discriminación de las razas lecheras constituye otra presión para que las URF subordinen la actividad lechera a la cría, sosteniendo hatos con características que les permitan continuar integradas a la cadena de carne de bovino, a pesar del menor rendimiento en leche.

Las condiciones de producción del becerro son definidas a través de la demanda y controladas mediante la relación de dependencia de las URF respecto a los intermediarios. A consecuencia de este control, las unidades familiares son tomadoras de precios; su poder de negociación sobre el precio está limitado por los compromisos financieros establecidos con el intermediario y por la propia escala de producción, que resulta poco significativa para los acopiadores. No obstante, esta circunstancia no es exclusiva de las URF; en la red de intermediación, los actores de cada fase toman el precio establecido en la siguiente e incluso en la UGRS el mercado estadounidense constituye la referencia para el establecimiento de los precios de la subasta ganadera.

En términos de las decisiones de las URF sobre los recursos destinados a la cría de becerros, es claro que ésta resulta prioritaria en relación a la ordeña. Las familias están dispuestas a asumir la reducción de sus ingresos por venta de queso en aras de sostener la cría, como se constata en la práctica de dejar de ordeñar para garantizar la terminación del becerro a un peso conveniente para su entrega en octubre. Los argumentos para justificar este tipo de decisiones están relacionados con la condición cautiva que se vive en la cadena. Las URF están comprometidas con créditos que deben cubrir al momento de la entrega de los becerros y procuran liquidarlos totalmente; por esta razón, consideran al becerro como una garantía de ahorro anual para enfrentar dichos compromisos.

A pesar de que las unidades familiares están organizadas en torno a la cría, lo atomizado de su oferta no les permite tener representatividad. Uno de los intermediarios entrevistados señala que de Cobachi recibe un promedio de cincuenta becerros por año, sin embargo, él maneja alrededor de seiscientos becerros en ese periodo, lo que significa que la oferta total de Cobachi sólo cubre $8 \%$ de su demanda. Con base en el censo ganadero de 2011, se puede calcular que las URF del ejido tienen un hato promedio de 23 vientres, lo que les permite producir un máximo de seis becerros machos al año, cantidad que sólo representa $1 \%$ de la demanda total del intermediario. 
La representatividad de la oferta se reduce más al comparar las existencias del intermediario con la oferta global de becerros en Sonora. En 2011, el estado exportó un total de $232680^{13}$ becerros machos, por lo que la cantidad de animales que manejan los intermediarios en contacto directo con los productores de Cobachi resulta insignificante, aunque en términos del ganado en pie demandado por EU a México, ${ }^{14}$ la oferta sonorense resulte significativa: $16.3 \%$ del total en 2011. Estas condiciones refuerzan lo que Gereffi, Humphrey y Sturgeon (2005) denominan dependencia transaccional, garantizando una oferta cautiva para las empresas líderes de la cadena, que en este caso se encuentran allende la frontera.

Si bien en EU el inventario ganadero ha disminuido, la producción de carne se ha incrementado considerablemente, lo que indica que su productividad mejoró en el periodo, pero también que ha suplido su demanda de ganado para la engorda y la matanza con importaciones en pie de otros países. El informe de la industria ganadera del Departamento de Agricultura de Estados Unidos (USDA, 2010) señala que de 1979 a 2009 la producción de carne ha crecido $22 \%$, mientras que el inventario ganadero se ha reducido en $15 \%$. El ganado mexicano y el canadiense han sustituido al estadounidense dentro del inventario de EU. En la actualidad, México y Canadá son el principal mercado de importación ganadera de ese país (cuadro 5), sin embargo, el canadiense lo importan listo para el sacrificio, mientras que el mexicano lo compran para engorda. Esto constituye una posición desventajosa en cuanto a la generación de valor agregado y es reflejo de la integración cautiva de los actores de la cadena en lado mexicano de la frontera.

Por último, es posible realizar un ejercicio comparativo de la apropiación de ingresos entre los actores de la cadena, con base en los datos proporcionados por uno de los intermediarios que recibe becerros en Cobachi y exporta directamente el ganado. Al momento de la entrevista, compraba el becerro a las URF en MXN 32 por kilogramo y recibía becerros de $180 \mathrm{~kg}$ en promedio, lo que para las familias significaba un ingreso por cabeza de MXN 5 760, producto de 17 meses de inversión considerando nueve meses de gestación y ocho de cría. El intermediario vendía en la frontera a MXN 41.38 por kilogramo con entregas cada 45 días, durante los cuales alimentaba los becerros acopiados y lograba obtener un sobrepeso que no debía superar el margen de las 600 libras $(272 \mathrm{~kg}$ ) impuesto por los compradores. De esta forma, entregaba animales con un peso de 220 a

${ }^{13}$ Datos de 2011, exportación de ganado en pie, machos, obtenidos de UGRS (s.f.).

${ }^{14}$ En 2011, Estados Unidos recibió de México un total de 1421189 cabezas de ganado para engorda y sacrificio (USDA, 2012) 
$272 \mathrm{~kg}$, que supone un aumento de entre 40 y $92 \mathrm{~kg}$, para un promedio de $246 \mathrm{~kg}$ por animal a un precio de MXN 10 180. En términos simples, un ingreso de MXN 4420 por 45 días, o menos. De este ingreso, debía descontar los gastos en alimento, transporte, impuestos y medicinas, así como asumir las posibles pérdidas por la muerte de uno o varios animales durante el traslado o por el rechazo de becerros no aptos desde el punto de vista del broker en la frontera, que en términos generales son los mismos conceptos que deben cubrir las familias durante el proceso de producción en sus ranchos, con excepción del transporte. Con base en estos datos, es posible estimar que las URF proveedoras de este intermediario retuvieron $57 \%$ de los ingresos finales por becerro, mientras que aquél se apropió de $43 \%$. De aquí se infiere que las familias ganaderas se encuentran en desventaja respecto al intermediario en la cadena de carne de bovino, ya que éste retiene más de dos quintas partes del precio final del producto con menos de la décima parte del tiempo invertido por las primeras. Esto se refuerza si se toma en cuenta que los ingresos por la venta de becerros significan sólo $15 \%{ }^{15}$ de los ingresos anuales totales de la actividad pecuaria de las URF en Cobachi.

Cuadro 5. Importaciones de ganado hechas por EU

\begin{tabular}{ccc}
\hline \multirow{2}{*}{ Año } & \multicolumn{1}{c}{ México } & Canadá \\
\cline { 2 - 3 } & & cabezas \\
\hline 2007 & 1090094 & 1404871 \\
2008 & 702661 & 1581303 \\
2009 & 940869 & 1061005 \\
2010 & 1221111 & 1062774 \\
2011 & 1421189 & 686114 \\
\hline
\end{tabular}

Fuente: USDA (2012).

\section{COMPARACIÓN DE LA CAPACIDAD DE GOBERNANZA DE LAS URF EN LAS CADENAS PECUARIAS}

En el cuadro 6 se presenta una síntesis comparativa de los resultados obtenidos en las variables de gobernanza por cadena. Estos indicadores permiten concluir

\footnotetext{
${ }^{15}$ Datos calculados con base en un hato promedio de treinta vientres y los precios vigentes de queso y becerros en julio de 2011 .
} 
que las URF, tanto las que sólo producen queso, como los queseros, logran una mayor capacidad de gobernanza en la cadena de lácteos, que cuando participan como criadoras de becerro en la cadena de carne.

En la cadena de lácteos, el mayor nivel de gobernanza se expresa desde el inicio de la interacción entre las URF y los queseros, que desarrollan relaciones flexibles y solidarias. Este rasgo se presenta también en la siguiente fase de intermediación, con los comercios de Hermosillo, donde la mayor capacidad de gobernanza de los queseros se manifiesta cuando actúan como proveedores únicos. Particularmente, la conservación del carácter artesanal del producto, con un proceso de producción y características que se definen en función de los saberes locales e incluso de las prácticas culinarias heredadas por cada familia, representa una ventaja a lo largo de la cadena hasta el consumo final.

\section{Cuadro 6. Determinantes de gobernanza dentro de las cadenas pecuarias}

\begin{tabular}{|c|c|c|c|c|c|c|c|}
\hline \multirow[b]{2}{*}{ Cadena } & \multicolumn{3}{|c|}{ Complejidad de transacciones } & \multicolumn{2}{|c|}{$\begin{array}{l}\text { Capacidad de los } \\
\text { proveedores } \\
\text { para cubrir la demanda }\end{array}$} & \multirow{2}{*}{$\begin{array}{l}\text { Retención } \\
\text { de } \\
\text { ingresos }\end{array}$} & \multirow{2}{*}{$\begin{array}{c}\text { Capacidad } \\
\text { de } \\
\text { gobernanza }\end{array}$} \\
\hline & $\begin{array}{l}\text { Tipo de } \\
\text { relaciones }\end{array}$ & $\begin{array}{l}\text { Características } \\
\text { del producto } \\
\text { y condiciones } \\
\text { de producción }\end{array}$ & $\begin{array}{c}\text { Fijación } \\
\text { del precio }\end{array}$ & $\begin{array}{l}\text { Recursos } \\
\text { destinados a } \\
\text { la cadena }\end{array}$ & $\begin{array}{l}\text { Representatividad } \\
\text { respecto a la } \\
\text { demanda }\end{array}$ & & \\
\hline $\begin{array}{c}\text { De } \\
\text { lácteos }\end{array}$ & Equilibradas & $\begin{array}{l}\text { Definidas } \\
\text { de modo } \\
\text { local }\end{array}$ & Negociada & $\begin{array}{c}\text { No } \\
\text { prioritarios }\end{array}$ & Significativa & Alta & Alta \\
\hline $\begin{array}{l}\text { De } \\
\text { carne }\end{array}$ & $\begin{array}{c}\text { De } \\
\text { dependencia }\end{array}$ & $\begin{array}{l}\text { Definidas } \\
\text { de modo } \\
\text { externo }\end{array}$ & Impuesta & Prioritarios & No significativa & Baja & Baja \\
\hline
\end{tabular}

Fuente: Elaboración propia con base en esquema de Gereffi, Humphrey y Sturgeon (2005, p. 67).

En contraste, la situación cautiva en la que se encuentran las URF en la cadena de carne de bovino se sintetiza en el cuadro: relaciones de dependencia; imposición externa de las condiciones de producción, las características del producto y el precio; subordinación de la producción quesera a la cría de becerro; baja representatividad respecto a la demanda, y reducida participación relativa en los ingresos generados en la cadena, estimados a través del precio final del producto. En este sentido, el estudio demuestra que el hecho de participar en una cadena de orden global no garantiza las mejores condiciones de subsistencia para las familias, ya que las subordina y minimiza sus posibilidades de negociación 
ante los grandes corporativos industriales de la carne en EU. En términos de Gereffi, Humphrey y Sturgeon (2005), son transaccionalmente dependientes y fácilmente reemplazables por otros proveedores.

Por otra parte, la producción quesera de las URF representa una actividad de ciclo corto, es decir, los productores obtienen ingresos constantes y en Cobachi se practica durante todo el año. Las entradas para las familias por este concepto son diarias. Esta actividad constituye su principal fuente de ingresos, aproximadamente $85 \%$ de sus percepciones anuales. No obstante, debido a la subordinación de esta actividad respecto a la cría de becerro, durante los meses de lluvia es posible que las URF decidan sacrificar la producción de queso proveniente de vacas con becerros machos para obtener un mayor peso de los animales a venderse en octubre. La condición cautiva en la cadena de carne trasciende incluso sus condiciones de participación en la cadena de lácteos, poniendo en competencia los recursos destinados por la familia a una u otra actividad.

Si bien, con base en las entrevistas realizadas, es posible afirmar que los productores están conscientes de sus desventajas en la cadena de la carne, su permanencia en ella se explica por la necesidad de resolver su ciclo de endeudamiento, aunque también está relacionada con la política de gubernamental que aún identifica el desarrollo con actividades productivas integradas a los mercados globales.

\section{CONCLUSIONES}

Las URF del ejido Cobachi están integradas en dos cadenas de valor, una de lácteos a nivel local-regional, y otra de carne de bovino a nivel internacional. Actualmente, estas actividades constituyen su principal fuente de ingresos, por lo que las decisiones que toman sobre sus condiciones de integración a una y a otra, se reflejan directamente en sus beneficios y, en términos de la economía familiar, en la subsistencia de sus unidades de producción.

La metodología de Gereffi, Humphrey y Sturgeon (2005) para el estudio de las cadenas globales resultó de gran utilidad con el fin de realizar una comparación de estas condiciones de integración en términos de la gobernanza que logran estas unidades familiares en las cadenas pecuarias. Como señalan estos autores, el nivel de gobernanza que ejercen los actores en sus encadenamientos define los beneficios que son capaces de obtener de su participación en ellos, no solo a nivel de empresa o familia, sino en términos del posicionamiento del país, o bien, para adecuarlo al caso, de la comunidad o grupo social al que pertenecen. 
De esta forma, para las familias rurales, transitar de un menor a un mayor nivel de gobernanza en la cadena de la carne es indispensable para mejorar sus condiciones de subsistencia. Sin embargo, en la medida que se trata de una cadena global, cuyos núcleos de decisión se encuentran en los eslabones industriales de EU, es difícil generar iniciativas locales que puedan mejorar la posición de estas familias rurales. De acuerdo con Gereffi, Humphrey y Sturgeon (2005) es posible que las relaciones equilibradas o de mutua dependencia se sostengan aunque se trate de actores dispersos de la cadena, pero ello implica que existan de antemano lazos tan fuertes como los familiares o étnicos, lo cual difícilmente puede suceder cuando en la cadena participan grandes corporativos. ${ }^{16}$

Una comparación entre los beneficios sociales que genera una economía basada en la dinámica de este tipo de empresas, respecto a una centrada en la producción local de pequeña escala fue realizada por Goldschmidt en 1947 (citado por Lyson, 2004, p. 374), quien llevó a cabo un ejercicio en dos comunidades agrícolas del Valle Central de California: la primera basaba su economía en pequeñas granjas familiares, mientras la otra estaba rodeada de grandes empresas agrícolas administradas corporativamente. Los resultados del estudio demostraron que la segunda comunidad registró el entorno social más pobre en cada prueba efectuada. En un estudio más reciente, Chauvet (2010) llega a conclusiones similares cuando analiza los efectos que el establecimiento de grandes corporativos, como Walmart, tiene sobre las economías locales. Esta autora señala que con base en una competencia desleal, a través de un control monopsónico de precios, se elimina a los intermediarios y se presiona a los productores de tal forma que sólo los más capitalizados sobreviven, lo que genera como consecuencia la ruptura del tejido social (Chauvet, 2010, p. 54).

En estos términos, la alternativa más adecuada para las familias rurales estudiadas parece ser el fortalecimiento de la cadena de lácteos, ya que en ella participan de manera equilibrada en el sentido de la gobernanza relacional. Asimismo, sus redes familiares dominan la cadena hasta los eslabones finales, en algunos casos, por lo que estimular la producción quesera conlleva la virtud de potenciar el desarrollo de toda la comunidad, incluso de aquellos que residen, pero se mantienen vinculados, en la ciudad de Hermosillo. Por último, como resultado del ejercicio, destacan dos elementos que deben ser eje de cualquier estrategia para fortalecer esta cadena: la calidad artesanal del producto y el dominio de las redes familiares sobre la dinámica de intercambio.

\footnotetext{
${ }^{16}$ Cargill y Tyson entre los principales; para ampliar esta información, véase Taddei (2006).
} 


\section{REFERENCIAS BIBLIOGRÁFICAS}

Andablo, Araceli, y Hernández, María del Carmen (2011), "Elementos para la constitución de un SIAL lácteo en Sonora: la quesería artesanal en el ejido Cobachi”, en F. Boucher y V. Brun (eds.), De la leche al queso. Queserías rurales en América Latina, México, IICA/CIRAD/Miguel Ángel Porrúa, pp. 237-268.

Bravo, Luis Carlos; Doode, Shoko; Castellanos, Alejandro, y Espejel, Ileana (2010), "Políticas rurales y pérdida de cobertura vegetal. Elementos para reformular instrumentos de fomento agropecuario relacionados con la apertura de praderas ganaderas en el noroeste de México", Región y Sociedad, 22 (48), pp. 3-35.

Bolwig, Simon; Ponte, Stefano; Du Toit, Andries; Riisgaard, Lone, y Halberg, Niel (2010), "Integrating poverty and environmental concerns into value-chain analysis: a conceptual framework", Development Policy Review, 28 (2), pp. 173-194.

Camou, Ernesto (1998), De rancheros, poquiteros, orejanos y criollos, Zamora, Michoacán, CIAD/El Colegio de Michoacán.

Catalán, César Gioberti (2012) "La gobernanza en el proceso de integración de las familias rurales a las cadenas pecuarias. Estudio de caso del ejido Cobachi”, tesis de licenciatura, Universidad de Sonora, México.

Chauvet, Michel (2010), "El sistema agroalimentario mundial y la ruptura del tejido social”, en C. J. Maya y M. C. Hernández (eds.), Globalización y sistemas agroalimentarios, México, UAS/CIAD, AC/ AMER/Juan Pablos, pp. 41-60.

CONEVAl (2010), "Informe de medición de la pobreza, Estados Unidos Mexicanos, 2010", en CONEVAL. Consultado el 11 de julio de 2012, en: www.coneval.gob. $\mathrm{mx} / \mathrm{cmsconeval} / \mathrm{rw} / \mathrm{pages} / \mathrm{medicion} /$ Pobreza_2010/Anexo_estadistico.es.do.

Cruz, Mirian; López, Carlos, y Schatan, Claudia (2004), Pequeñas empresas, productos étnicos y de nostalgia: oportunidades en el mercado internacional. Los casos de El Salvador y México, Serie Estudios y Perspectivas 7, México, CEPAL.

Gereffi, Gary; Humphrey, John, y Sturgeon, Timothy (2005), “The governance of global value chains", Review of International Political Economy, 12 (1), pp. 78-104.

Gereffi, Gary, y Korzeniewicz, Miguel (1994), Commodity Chains and Global Capitalism [en línea]. Consultado el 10 de junio de 2012, en: www.questia.com/ PM.qst? $\mathrm{a}=\mathrm{o} \& \mathrm{~d}=22905283$.

Hernández, María del Carmen; Andablo, Araceli, y Ulloa, Antonio (2011), "Evaluación y perspectivas de las estrategias de integración de la agricultura familiar a las cadenas pecuarias en Sonora", en B. A. Cavallotti, B. Ramírez, F. E. Martínez, C. F. Marcof y A. C. Vargas (eds.), La ganadería ante el agotamiento de los para- 
digmas dominantes, vol. 1, México, Universidad Autónoma de Chapingo/COLPOS/COECYT Michoacán/ICAR, pp. 249-264.

(2012), "Agricultura familiar sustentable y seguridad alimentaria. ¿Una salida viable a la crisis alimentaria?", en M.C. Hernández y J.M. Meléndez (eds.), Alimentación contemporánea: un paradigma en crisis y respuestas alternativas, México, Centro de Investigación en Alimentación y Desarrollo, AC, pp. 235-267. Hernández, María del Carmen, y Camou, Ernesto (1994), "Los intermediarios en la exportación de becerros: Una red de flujos de productos, recursos y relaciones sociales", Estudios Sociales, 4 (8), pp. 165-196.

Hernández, María del Carmen, y Ulloa, Antonio (2000), “Intermediarismo ¿Un mal necesario?: Las paradojas de la integración de los productores rurales al mercado internacional de bovinos", Estudios Agrarios, 0 (14), pp.61-80. Existe una versión en línea disponible en: www.pa.gob.mx/publica/rev_14/Mar\%C3\%ADa\% 20del\%20Carmen.pdf.

Hufty, Marc (2009), The governance analytical framework [en línea]. Consultado el 8 de julio de 2012, en: http:/graduateinstitute.ch/webdav/site/developpement/ groups/hufty_greg/public/Governance_Analytical_Framework.pdf.

INEGI (1980), “X Censo General de Población y Vivienda”, en Instituto Nacional de Estadistica y Geografia. Consultado el 24 de mayo de 2012, en: www.inegi.org. $\mathrm{mx} / \mathrm{est} / \mathrm{contenidos/proyectos/ccpv/cpv1980/default.aspx}$

INEGI (2010), "Censo de Población y Vivienda", en Instituto Nacional de Estadística y Geografia. Consultado el 24 de mayo de 2012, en: www.inegi.org.mx/est/contenidos/proyectos/ccpv/cpv2010/Default.aspx

Kaplinsky, Raphael, y Morris, Mike (2002), A Handbook for Value Chain Research, Institute of Development Studies [en línea]. Consultado el 12 de junio de 2012, en: www.srp-guinee.org/download/valuechain-handbook.pdf.

Ley de Desarrollo Rural Sustentable del Estado de Sonora (2009), Congreso del Estado de Sonora [en línea]. Consultado el 8 de julio de 2012, en: www.congresoson. gob.mx/Leyes_Archivos/doc_298.pdf.

Lyson, Thomas (2004), "Commodity Agriculture, Civic Agriculture and the Future of US Farming”, Rural Sociology, 69 (3), pp. 370-385.

Madelin, Robert (2001), "Strengthening Europe's contribution to world governance", en White Paper on Governance Working. Consultado el 25 de noviembre de 2011, en: http://ec.europa.eu/governance/areas/group11/report_en.pdf.

Paz, María (2008), “Tensiones de la gobernanza en el México rural”, Política y Cultura, 0 (30), pp. 193-208. 
Pérez, Emma (1993), Ganadería y campesinado en Sonora, Sonora, Consejo Nacional para la Cultura y las Artes.

Taddei, Cristina (2006), "Estrategias de mercado de las firmas líderes de la industria alimentaria", Estudios Sociales, 14 (28), pp. 68-106.

UGRS (s.f), "Subasta", en Unión Ganadera Regional de Sonora. Consultado el 15 y el 25 de julio de 2012, en: www.unionganadera.com/seccion.php?id=24.

UNDP (1997), Governance for sustainable human development. A UNDP policy document, United Nations Development Programme [en línea]. Consultado el 7 de mayo de 2012, en: http://mirror.undp.org/magnet/policy/.

USDA (2010), “Overview of the United States Cattle Industry”, en National Agricultural Statistics Service (NASS), Agricultural Statistics Board, United States Department of Agriculture (USDA). Consultado el 17 de febrero de 2011, en: www. nass.usda.gov.

(2012) "Cattle: Annual and cumulative year-to-date U.S. trade - All years and countries", en National Agricultural Statistics Service (NASS), Agricultural Statistics Board, United States Department of Agriculture (USDA). Consultado el 24 de agosto de 2012, en www.ers.usda.gov/data-products/livestock-meat-international-trade-data.aspx. 